\title{
Cold-Shock Resistance of Activated Sludge Microorganisms Strengthened by a Static Magnetic Field
}

\author{
Chuan Niu ${ }^{1,2 *}$, Junfeng Wu ${ }^{1}$, Hong Ling', Lianjun Wang ${ }^{2}$ \\ ${ }^{1}$ Jiangsu Key Laboratory of Environmental Engineering, Jiangsu Provincial Academy of Environmental Science, \\ Nanjing, China \\ ${ }^{2}$ School of Environmental and Biological Engineering, Nanjing University of Science and Technology, \\ Nanjing, China
}

Received: 21 January 2018

Accepted: 26 March 2018

\begin{abstract}
We studied the anti-cold shock performance of activated sludge microbes (ASM) with magnetic field (MF) strengthening under slow and rapid cooling and rewarming. From stage S3 to S4, the TTC-DHA (triphenyltetrazolium chloride dehydrogenase) of reactor $\mathrm{A}_{2}$ and $\mathrm{B}_{2}$ were $98.5 \%$ and $72.5 \%$ higher than that of reactor $A_{1}$ and $B_{1}$, which showed that MF had a better strengthening effect on TTC-DHA under slow temperature variation than that under rapid temperature variation. MF had a definite strengthening effect on relief and inhibition of cell membrane lipid peroxidation and low-temperature injury, which was indicated by SOD (superoxide dismutase), CAT (catalase), and MDA (malonaldehyde), while the MF strengthening effect on SOD and CAT activity was not stable under rapid cooling and rewarming. The MF had little effect on phospholipid fatty acid (PLFA) diversity of ASM under slow cooling, but had higher PLFA diversity on that under rapid cooling. Optimal MF strengthening application under different temperature variation mode is supposed to be a potential pathway to strengthen the activity and cold resistance of ASM and improve the efficiency of wastewater treatment in low temperatures.
\end{abstract}

Keywords: temperature variation, activated sludge, magnetic field strengthening, phospholipid fatty acid, microbial diversity

\section{Introduction}

Low temperature $\left(0-10^{\circ} \mathrm{C}\right)$ is a key limiting factor for biochemical wastewater treatment methods [1]. The fact that varying cooling speed rate can cause different degrees of microbial cell damage has been studied.

*e-mail: niuchuan11@163.com
Rapid cooling causes intracellular ice damage, while slow cooling leads to microbial solution loss (solution damage) [2]. In a biological wastewater treatment process, the temperature variation rate is relative to the microbe, which has great influence on wastewater treatment efficiency [3-4].

Under normal temperatures, the generation and elimination of active oxygen in vivo keeps balance, while the active oxygen tends to excessive accumulation 
under an extreme low-temperature environment (0$10^{\circ} \mathrm{C}$ ). The main forms of active oxygen contain superoxide anion radicals, hydrogen peroxide $\left(\mathrm{H}_{2} \mathrm{O}_{2}\right)$, and oxygen free radical $(\cdot \mathrm{OH})$. The reactive oxygen will react with membrane lipids, proteins, DNA [5], and other biological large molecules, resulting in the peroxidation of cell membrane, the accumulation of membrane lipid oxidation product malondialdehyde (MDA), damage to the membrane structure, the increase of membrane permeability, lysosomal disruption and cell lysis, the decrease of cell membrane fluidity, and abnormity of cell physiological function [6]. Antioxidant enzymes such as superoxide dismutase (SOD) and catalase (CAT) are the main tools for eliminating reactive oxygen. The main function of SOD and CAT is to transform the superoxide anion free radical to $\mathrm{H}_{2} \mathrm{O}_{2}$ [7] as the protective enzyme defense system within the organisms. The activity of SOD and CAT indirectly reflects the ability of microbes to remove oxygen free radicals, and the MDA content indirectly reflects the severity of microbe attacked by free radical.

Increasing attention has been directed to the possibility of improving wastewater treatment processes by applying static magnetic fields (MF), which is a new method to intensify the elimination of wastewater pollution. The MF does not require extensions of existing plants or constructing expensive bioreactors [8], and can be directly applied on the original wastewater treatment structures. MF strengthening on activated sludge microbes (ASM) has been applied to wastewater treatment at low temperature, and the intensity of 30 $\mathrm{mT}$ has proven to be more effective [9]. The microbial membrane's fluidity is weakened and the enzyme activity is inhibited at low temperatures, and MF strengthening has the potential to cover the shortage of lowtemperature limitation through affecting the orientation rearrangement of lipid bilayer and the activity center site of an enzyme [10]. Meanwhile, phospholipid fatty acid (PLFA) as the component of cell membrane will have corresponding variation at low temperatures, and analysis of this constituent makes it possible to obtain biochemical fingerprints of communities and yield information about the taxonomy, functions, physiology, and abundance of community members [11].

Table 1. Reactor operation state

\begin{tabular}{|c|c|c|c|c|}
\hline Reactor code & $\mathrm{A}_{1}$ & $\mathrm{~A}_{2}$ & $\mathrm{~B}_{1}$ & $\mathrm{~B}_{2}$ \\
\hline Magnetic field & without & with & without & with \\
\hline $\begin{array}{c}\text { Temperature } \\
\text { variation }\end{array}$ & slow & slow & rapid & rapid \\
\hline Stage 1 & $25^{\circ} \mathrm{C}$ & $25^{\circ} \mathrm{C}$ & $25^{\circ} \mathrm{C}$ & $25^{\circ} \mathrm{C}$ \\
\hline Stage 2 & 25 to $0^{\circ} \mathrm{C}$ & 25 to $0^{\circ} \mathrm{C}$ & 25 to $0^{\circ} \mathrm{C}$ & 25 to $0^{\circ} \mathrm{C}$ \\
\hline Stage $3-4$ & $0^{\circ} \mathrm{C}$ & $0^{\circ} \mathrm{C}$ & $0^{\circ} \mathrm{C}$ & $0^{\circ} \mathrm{C}$ \\
\hline Stage 5 & 0 to $25^{\circ} \mathrm{C}$ & 0 to $25^{\circ} \mathrm{C}$ & 0 to $25^{\circ} \mathrm{C}$ & 0 to $25^{\circ} \mathrm{C}$ \\
\hline Stage 6-7 & $25^{\circ} \mathrm{C}$ & $25^{\circ} \mathrm{C}$ & $25^{\circ} \mathrm{C}$ & $25^{\circ} \mathrm{C}$ \\
\hline
\end{tabular}

This experiment mainly studied the anti-cold shock performance of ASM activity with MF strengthening under slow and rapid cooling and rewarming. The variation laws of TTC-DHA, SOD, MDA, and CAT were researched. While PLFA and 16S rRNA analysis are combined to analyze the community structure and diversity of activated sludge at low temperatures, which reflect the MF strengthening effect on microbial resistance to cold-shock [12].

\section{Material and Methods}

\section{Bioreactor}

Four simulated sequencing batch reactors (SBR; reactors $A_{1}, A_{2}, B_{1}$, and $B_{2}$ ) made of plexiglass were operated with the working volume of $2 \mathrm{~L}$. The radii and heights of the reactors are $5 \mathrm{~cm}$ and $30 \mathrm{~cm}$, respectively. The operational state of the four reactors is listed as Table 1 .

Two heteropolar magnetic plates were placed in parallel beside reactors $A_{2}$ and $B_{2}$ in order to generate a static MF. The plate intervals were adjusted to assure that the center MF intensities were $30 \mathrm{mT}$, while reactors $A_{1}$ and $B_{1}$ were set as the control variable without exposure to any MF. The MF intensities were detected by a TM-701 Tesla Meter, Kanetec.

After adaptation at $25^{\circ} \mathrm{C}$ of the four reactors for $25 \mathrm{~d}$ in the temperature-controlled incubators, reactors $\mathrm{A}_{1}$ and $\mathrm{A}_{2}$ experienced slow cooling and rewarming process (temperature variation rate $=1.2^{\circ} \mathrm{C} / \mathrm{h}$ ), and reactors $B_{1}$ and $B_{2}$ experienced rapid cooling and rewarming (instantaneous transfer). The process experienced seven stages: S1 to S7. Stage S1 was running at $25^{\circ} \mathrm{C}$, stages $\mathrm{S} 2$ to $\mathrm{S} 4$ were cooling stages running at $0^{\circ} \mathrm{C}$ to simulate the most extreme low-temperature environment of wastewater treatment, and stages S5-S7 were rewarming stages running at $25^{\circ} \mathrm{C}$. Every stage lasted 5 days.

The synthetic wastewater consisted of $\mathrm{C}_{6} \mathrm{H}_{12} \mathrm{O}_{6}$ (1000 mg/L), $\mathrm{NH}_{4} \mathrm{Cl}(191 \mathrm{mg} / \mathrm{L})$, and $\mathrm{KH}_{2} \mathrm{PO}_{4}(44 \mathrm{mg} / \mathrm{L})$, diluted to a final COD of $200 \mathrm{mg} / \mathrm{L}$ at domestication stage and $400 \mathrm{mg} / \mathrm{L}$ at the experimental stage; the mass ratio of $\mathrm{C}: \mathrm{N}: \mathrm{P}$ was 100:5:1. Trace elements were included as well. The cycle time of the reactors was $12 \mathrm{~h}$ with $1000 \mathrm{~mL}$ wastewater and $1000 \mathrm{~mL}$ activated sludge aerated with an air pump $(3.0 \mathrm{~L} / \mathrm{min})$. The hydraulic retention time (HRT) was $10 \mathrm{~h}$ with a solid retention time (SRT) of 10 days. This process was operated in batch with filling, reaction, and settling times of $0.2 \mathrm{~h}$, $10 \mathrm{~h}$, and $1.8 \mathrm{~h}$, respectively. The oxygen concentration during this time was around $8.65 \mathrm{mg} / \mathrm{L}$ for the four reactors and no external $\mathrm{pH}$ control was applied during this study. The sludge for the inoculation in the reactors was collected from a local wastewater treatment plant in Nanjing, China and its concentration was about $4800 \mathrm{mg} / \mathrm{L}$. 


\section{Enzyme Activity and Malonaldehyde Content}

The TTC-DHA of microorganisms was analyzed according to Tracey's, with slight modification [13]. TTC as the artificial hydrogen acceptor will translate into TF (triphenyl formazan), which can be measured at $486 \mathrm{~nm}$. The yield was defined as $1 \mathrm{ug}$ TF per hour as a unit of enzyme activity.

Protein, MDA, SOD, and CAT contents were determined by the reagent kits provided by Nanjing Jiancheng bioengineering institute. Crude enzyme was extracted as follows: activated sludge was collected by centrifugation, added with normal saline, and broken in an icewater bath by ultrasonic. Protein content was determined by the method of Coomassie brilliant blue. SOD was detected by the method of WST-1 (water soluble tetrazolium salt). WST-1 and super oxide anion created by Xanthine oxidase catalysis react to form formazan dye, which can be inhibited by SOD. The SOD activity can be calculated by colorimetric analysis of the WST-1 product. CAT activity was measured by the visible light method. The reaction of CAT decomposing $\mathrm{H}_{2} \mathrm{O}_{2}$ can be stopped quickly by ammonium molybdate. The residual $\mathrm{H}_{2} \mathrm{O}_{2}$ and ammonium molybdate react to form light yellow complex, which can be detected at $405 \mathrm{~nm}$ to calculate CAT activity. MDA content was determined by the TBA (thiobarbituric acid) method. The MDA in the degradation products of lipid peroxide can be condensed with TBA, and generates red product, which has the maximum absorption peak at $532 \mathrm{~nm}$.

\section{Phospholipid Fatty acid Extraction and Nomenclature}

The PLFA extraction method was modified based on Balser's [14-16]. Briefly, $5 \mathrm{~mL}$ activated sludge was collected randomly from the middle level of the sedimental activated sludge layer in the reactors for three times and mixed evenly, and the mixture was stirred then centrifuged for 5 minutes with the supernatant discarded. Through separation, elution, saponification, methylation, and extraction, the resulting fatty acid methyl esters were prepared according to MIDI protocol and detected with an Agilent 7890 GC, and the results were analyzed using the MIDI Sherlock Microbial Identification System (MIDI, Newark, DE) [17]. Fatty acids were designated in terms of total number of carbon atoms, with the number of double bonds given after a colon, following the form $\mathrm{A}: \mathrm{B} \omega \mathrm{C}$, where $\mathrm{A}$ is the number of carbon atoms, $\mathrm{B}$ is the number of double bond, and $\mathrm{C}$ is the position of the first double bond from the $\omega$ or the molecule's aliphatic end. In branched chain fatty acids, the suffixes marked iso and anteiso present homotype and heterotype fatty chains, respectively.

\section{Statistical Analysis}

The enzyme activity values were expressed as the mean standard deviation. The data was statistically analyzed using SPSS Version 18.0 for Windows. The differences between the control and experimental groups were analyzed using one-way analysis of variance and LSD test. Values of $p<0.05$ were considered significant, and values of $\mathrm{p}<0.01$ were accepted as having high statistical significance. Meanwhile, $a, b$, and $c$ presented that $A_{2}$ relative to $A_{1}, B_{2}$ relative to $B_{1}$ and $B_{2}$ relative to $\mathrm{A}_{2}$ had significant differences.

The Shannon-Wiener index was generally defined as:

$$
H=-\sum_{i=1}^{\mathrm{s}} p_{i} \lg \left(p_{i}\right)
$$

...where $H$ was Shannon-Wiener index, $s$ was the total number of PLFA in each sample, and $p_{i}$ was the percentage of the peak area of PLFA to the total area of each sample. The GC assay peak areas were used to calculate values of $p_{i}$ for each PLFA, which were inserted into the equation above.

\section{Polymerase Chain Reaction-Denaturing Gradient Gel Electrophoresis Analysis for Bacterial Community}

Polymerase chain reaction (PCR) was performed with the primers $518 \mathrm{r}$ and $338 \mathrm{f}$ (with GC-clamp) under the following conditions: $94^{\circ} \mathrm{C} / 5 \mathrm{~min}$ denaturation step; 30 cycles of $94^{\circ} \mathrm{C} / 30 \mathrm{~s}, 58^{\circ} \mathrm{C} / 30 \mathrm{~s}$, and $72^{\circ} \mathrm{C} / 45 \mathrm{~s}$; and a final extension step at $72^{\circ} \mathrm{C} / 10 \mathrm{~min}$. Denaturing gradient gel electrophoresis (DGGE) was carried out in a DGGE system for the PCR products. Gels were photographed using Kodak 1D image analysis software after being stained with ethidium bromide. For further identification of DGGE bands in each sample, several representative DGGE bands were cut from the DGGE gel and amplified with the primes $518 \mathrm{r}$ and $338 \mathrm{f}$ (without GC-clamp), and then were sent for sequencing by Genscript, Nanjing.

\section{Results and Discussion}

\section{Triphenyltetrazolium Chloride Dehydrogenase}

The TTC-DHA of microbes can reflect the efficiency of substrate degradation under different temperature variation conditions [18-19]. Fig. 1 reflects the TTCDHA variation of four reactors under different periods of cooling and rewarming. After cooling, the TTC-DHA of each reactor was significantly reduced at stage S2. From stage S3 to S4, the TTC-DHA of reactor $\mathrm{A}_{2}$ and $\mathrm{B}_{2}$ increased, and were $98.5 \%$ and $72.5 \%$ higher than that of reactors $A_{1}$ and $B_{1}$, respectively. Reactor $A_{2}$ relative to $A_{1}$ had positive significant differences at stage $\mathrm{S} 2(\mathrm{p}=0.001)$ and negative significant differences at stages $S 3(p=0.001)$ and $S 4(p=0.002)$. The TTC-DHA of reactor $\mathrm{B}_{2}$ relative to $\mathrm{B}_{1}$ did not vary too much, and reactor $B_{2}$ relative to $A_{2}$ had negative 


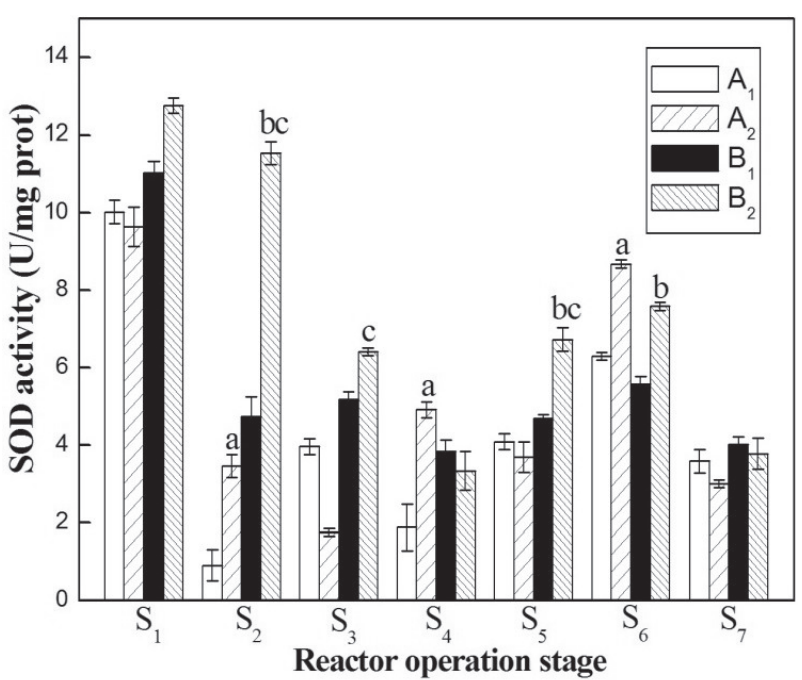

Fig. 1. TTC-DHA of activated sludge reactors in the process of temperature variation;

significant difference at stage $\mathrm{S} 3(\mathrm{p}=0.001)$. At stage $\mathrm{S} 5$, reactor $\mathrm{B}_{2}(\mathrm{p}=0.001)$ relative to $\mathrm{A}_{2}$ had negative significant difference, and the TTC-DHA of MF strengthening reactors were higher than that of control groups. At the whole stage of rewarming, the TTCDHA all improved and recovered to a certain extent, and reached the level before cooling, in which the TTCDHA variation ranges of reactors $A_{1}$ and $A_{2}$ were larger than those for reactors $\mathrm{B}_{1}$ and $\mathrm{B}_{2}$.

The four reactors were greatly affected by low temperature at the initial cooling stage of $\mathrm{S} 2$, but the TTC-DHA increase of reactors $\mathrm{A}_{2}$ and $\mathrm{B}_{2}$ at stages $\mathrm{S} 3$ and $\mathrm{S} 4$ compared to the control group indicates that the MF had a strengthening effect on TTC-DHA of ASM at cooling phase. The significant difference of reactor $A_{2}$ relative to $A_{1}$ showed that the $M F$ improved the TTC-DHA under slow cooling, while the low activity of reactor $\mathrm{B}_{2}$ after cooling demonstrated that rapid cooling greatly inhibited the TTC-DHA, and MF had poor strengthening effect on it [20]. After rewarming, the variations showed that rapid temperature change greatly affected TTC-DHA - with even the temperature returning to $25^{\circ} \mathrm{C}$, and the TTC-DHA cannot restore to normal state immedinately from low-temperature injury [21]. The significant difference of reactor $A_{2}$ relative to $B_{2}$ at stage $S 5$ showed that MF had a better strengthening effect on ASM under slow temperature variation than that under rapid temperature variation.

\section{Superoxide Dismutase Activity}

SOD is the most important enzyme for organism resistance to clear free radicals, which mainly scavenge vivo active oxygen $\left(\mathrm{O}^{2--}\right)$ [22]. Fig. 2 shows the SOD activity of activated sludge reactors in the process of cooling and rewarming variation. As can be seen, stage S1 has high SOD activity of four reactors at $25^{\circ} \mathrm{C}$. The SOD activity was all reduced after the start of

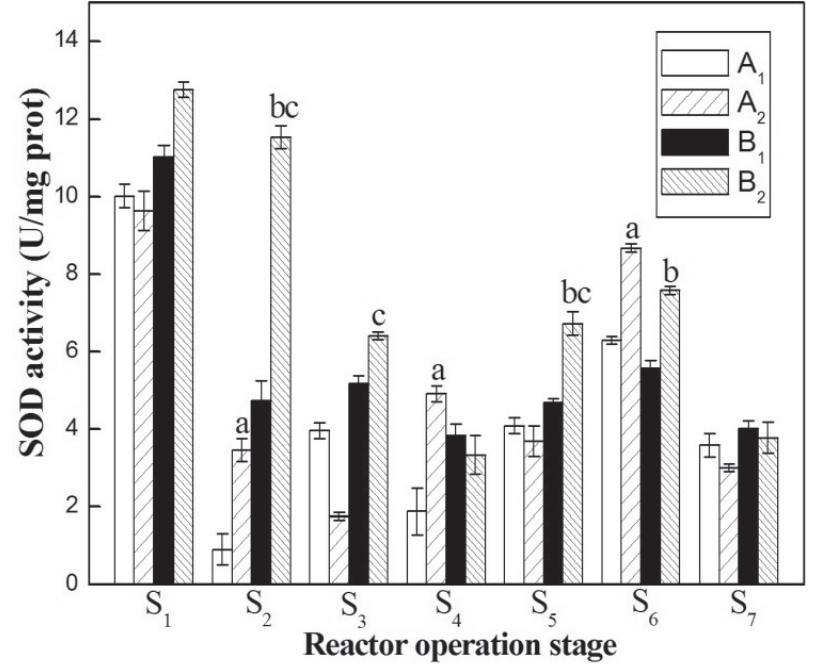

Fig. 2. SOD activity of activated sludge reactors in the process of temperature variation.

cooling, while the decline ranges of reactors $A_{1}$ and $A_{2}$ were larger and reactor $\mathrm{B}_{2}$ was the smallest. Compared to reactors $A_{1}$ and $B_{1}$, the SOD activity of reactors $A_{2}$ $(p=0.006)$ and $B_{2}(p=0.001)$ had significant differences, as well as reactor $B_{2}(p=0.001)$ relative to $A_{2}$. At the stage of continuous low-temperature condition (stage $\mathrm{S} 2$ to $\mathrm{S} 3)$, reactor $\mathrm{B}_{2}(\mathrm{p}=0.001)$ had significant difference with respect to reactor $\mathrm{A}_{2}$ at stage $\mathrm{S} 3$, as well as reactor $A_{2}(p=0.005)$ relative to $A_{1}$ at stage $S 4$. At the stage of rewarming (stage $S 5$ to $S 7$ ), reactor $B_{2}$ had significant differences to $\mathrm{B}_{1}(\mathrm{p}=0.03)$ and $\mathrm{A}_{2}(\mathrm{p}=0.01)$ at stage S5. At the continuous rewarming phase of stage S6, MF strengthening reactors $A_{2}(p=0.022)$ to $A_{1}$ and $B_{2}$ $(p=0.029)$ to $B_{1}$ all had significant differences.

Reactors $A_{1}$ and $A_{2}$ were under slow cooling, and exposure to low temperature for more than 24 $h$ at stage $S 2$, while reactors $B_{1}$ and $B_{2}$ were under rapid cooling, and transferred to the environment of $0^{\circ} \mathrm{C}$ instantaneously through adjusting the incubator temperature. The microbial cells of reactor $A_{1}$ and $A_{2}$ were damaged more severely, and biomass in reactor $B_{1}$ and $B_{2}$ were less affected, though they were all under dramatic temperature drop [23]. The results indicated that it is an accumulated process of low-temperature injury for microbial cells and SOD activity [24]. From stage $\mathrm{S} 3$ to $\mathrm{S} 4$, the SOD activity of reactor $\mathrm{A}_{2}$ remained stable, while reactor $\mathrm{B}_{2}$ showed a gradual decline in the overall trend, which demonstrated that rapid temperature variation and continual exposure time at low temperature increased the injury of microbial cells, and inhibited the activity of SOD. In the three phases of low temperature, the average SOD activity of reactor $A_{1}$ and $B_{1}$ were $45.0 \%$ and $52.4 \%$ lower than that of reactor $\mathrm{A}_{2}$ and $\mathrm{B}_{2}$, respectively. It showed that the MF had a definite strengthening effect on SOD activity at low temperature [25]. After warming, the SOD activity of four reactors were all improved and the significant differences of stages S6 and S7 indicated that the SOD 


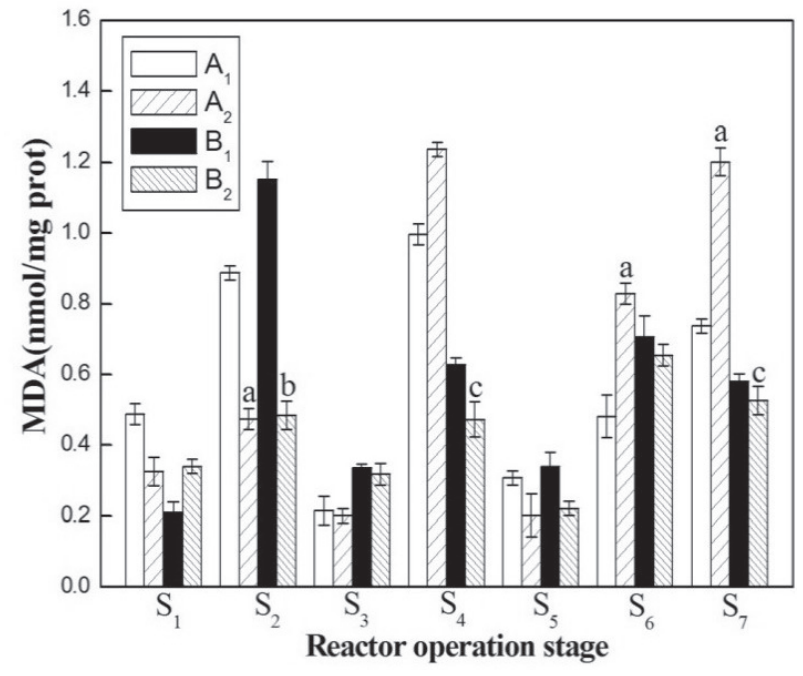

Fig. 3. MDA content of activated sludge reactors in the process of temperature variation.

activity recovery time was longer for a slow-cooling reactor, but the activity will become higher than that of under rapid cooling gradually, which meant that rapid temperature variation had a greater impact on SOD activity recovery [26].

\section{Malonaldehyde Content}

MDA is the product of lipid peroxidation, and the higher the MDA content, the greater damage degree the microbial membrane endures [27-28]. Fig. 3 shows the MDA content variation of different reactors during temperature changes. After cooling, the MDA content at stage $\mathrm{S} 2$ all increased for four reactors, in which reactors $A_{1}$ and $B_{1}$ increased rapidly, by $82 \%$ and $449.1 \%$ respectively compared to stage $\mathrm{S} 1$, while reactors $\mathrm{A}_{2}$ and $\mathrm{B}_{2}$ increased only by $45.5 \%$ and $42.2 \%$ respectively, and reactors $A_{2}(p=0.042)$ and $B_{2}(p=0.046)$ had significant differences compared with the control groups. At the phase of stage S2 to S4, the MDA contents of reactors $A_{2}$ and $B_{2}$ increased gradually, and $B_{2}(p=0.028)$ had significant differences at stage $\mathrm{S} 4$ compared to $\mathrm{A}_{2}$. During the rewarming period, the MDA content of $\mathrm{A}_{2}$ greatly increased, and had significant differences at stages $\mathrm{S} 6(\mathrm{p}=0.027)$ and $\mathrm{S} 7(\mathrm{p}=0.026)$ relative to the control group $\left(\mathrm{A}_{1}\right)$. However, the MDA content of $\mathrm{B}_{2}$ changed little, and was lower than that of $\mathrm{A}_{2}$ during $\mathrm{S} 5$ to $\mathrm{S} 7$. In addition, $\mathrm{B}_{2}(\mathrm{p}=0.006)$ had significant differences with $\mathrm{A}_{2}$ at $\mathrm{S} 7$.

At the initial cooling stage, the decreasing temperature aggravated lipid peroxidation of cell membrane, causing damage to the microbial cell, and the membrane lipid oxidation was more serious under rapid cooling [29]. From S2 to S4, the significant differences of $\mathrm{A}_{2}$ and $\mathrm{B}_{2}$ compared with the respective control group indicated that the MF had a strengthening effect on the resistance to cell low-temperature injury. The MDA contents of four reactors decreased at stage

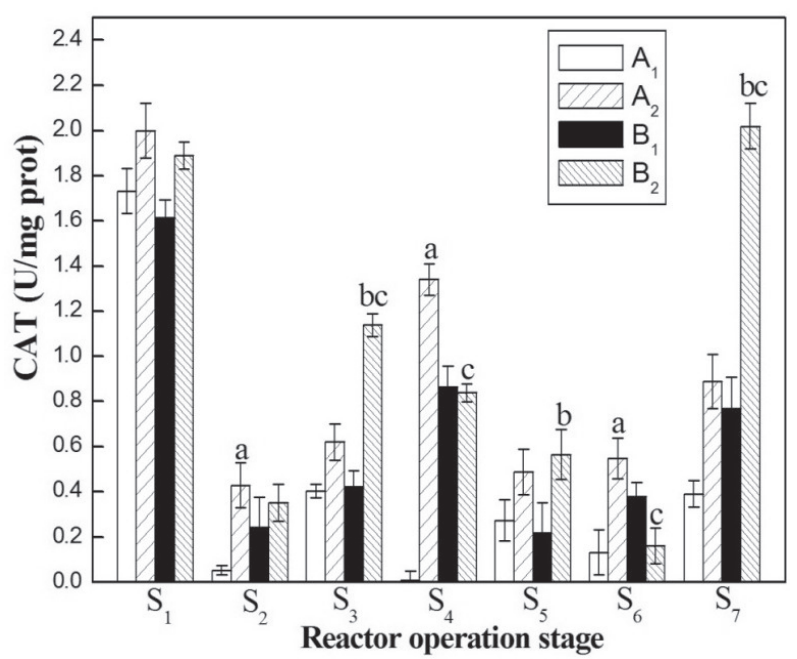

Fig. 4. CAT activity of activated sludge reactors in the process of temperature variation.

S5, but all increased from S6 to S7, and exceeded that of the initial reactor operation phase of $\mathrm{S} 1$ under moderate temperature. The reason is that the metabolism of microbial cells become stronger to repair the damaged cells, simultaneously the quantity of dead cell membrane was transformed to MDA [30]. The MDA content of reactor $B_{2}$ was lower than that of $B_{1}$ for the whole operation phase with the significant differences of MDA content of $\mathrm{B}_{2}$ to $\mathrm{A}_{2}$ at $\mathrm{S} 4$ and $\mathrm{S} 7$, which demonstrated that the MF had a better strengthening effect on the relief and inhibition of cell membrane lipid peroxidation and low-temperature injury [31].

\section{Catalase Activity}

CAT is an important endogenous active oxygen scavenger that can remove $\mathrm{H}_{2} \mathrm{O}_{2}$ and $\cdot \mathrm{OH}$ in vivo [32]. Fig. 4 shows the CAT activity variation of the four reactors during cooling and rewarming. At the initial stage of cooling, the CAT activity of four reactors all greatly decreased compared to that at $25^{\circ} \mathrm{C}$, but the CAT activities of $\mathrm{A}_{2}$ and $\mathrm{B}_{2}$ with $\mathrm{MF}$ were higher than that in the control group. $A_{2}$ relative to $A_{1}$ at $S 2(p=0.006)$ and $\mathrm{S} 4(\mathrm{p}=0.001), \mathrm{B}_{2}$ relative to $\mathrm{B}_{1}$ at $\mathrm{S} 3(\mathrm{p}=0.003)$, and $\mathrm{B}_{2}$ relative to $A_{2}$ at $S 3(p=0.017)$ and $S 4(p=0.018)$ all had significant differences. At S5, the CAT activity of the four reactors did not restore to the initial state of $\mathrm{S} 1$, but increased at S7. The CAT activity of $A_{2}(p=0.003)$ over the whole rewarming phase and $B_{2}$ at $S 5(p=0.027)$ and $\mathrm{S} 7(\mathrm{p}=0.001)$ all had significant differences compared to respective control groups. And $\mathrm{B}_{2}$ at $\mathrm{S} 6(\mathrm{p}=0.004)$ and S7 ( $p=0.001)$ had significant differences, but it was a negative significant difference at S6.

After cooling, the CAT activity of $\mathrm{A}_{2}$ and $\mathrm{B}_{2}$ were higher than that of $\mathrm{A}_{1}$ and $\mathrm{B}_{1}$, which indicated that the MF had a strengthening effect on CAT activity of ASM. During the whole cooling phase, the significant difference of $A_{2}$ relative to $A_{1}$ showed that $M F$ had 


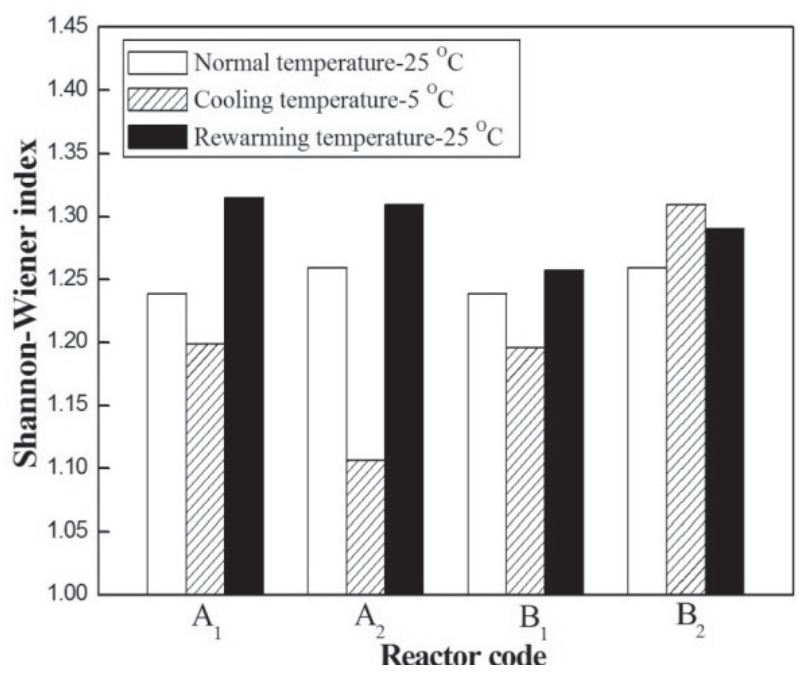

Fig. 5. Shannon-Wiener diversity indices of PLFA in the process of temperature variation.

a strengthening effect on CAT activity under slow cooling [33-34]. At the rewarming phase, the CAT activity of every reactor could not recover, which demonstrated that the CAT activity was inhibited by low temperature, and it needed more time to restore after rewarming. The significant difference of $\mathrm{A}_{2}$ relative to $\mathrm{A}_{1}$ after rewarming showed that MF had improved the CAT activity of slow cooling and rewarming. While the positive and negative significant difference of $B_{2}$ relative to $\mathrm{B}_{1}$ explained that the MF strengthening effect was not stable under rapid cooling and rewarming [35-36].

\section{Shannon-Wiener Diversity Analysis of Phospholipid Fatty Acid}

At every stage of THE cooling and warming processes there were a total of 42 species of PLFA counted by carbon chain distribution from $\mathrm{C} 10$ to $\mathrm{C} 20$. In order to investigate the richness and evenness of PLFA, which was the reflection of community diversity, Shannon-Wiener diversity analysis was applied [37].

The PLFA Shannon-Wiener diversity indices of the four reactors are shown in Fig. 5. As can be seen, the indices of $A_{1}, A_{2}$, and $B_{1}$ were lower than that under medium temperature, and the decline range of $A_{2}$ was the largest at the end-cooling stage, while the index of $\mathrm{B}_{2}$ increased compared with that at $25^{\circ} \mathrm{C}$. At the end warming stage, the indices of the four reactors all recovered to the level before cooling.

Low temperature will inhibit the growth and activity of mesophilic microbes, leading to dormancy and death, and cold adapted microorganism gradually becomes the dominant bacteria group [38]. But due to the slow growth rate and long generation, the quantity of microbes at low temperature is difficult to reach the level of mesophilic microorganism, which results in overall activity reduction, species number, and PLFA diversity decrease. After rewarming, microbes began to multiply quickly, the biomass and species of ASM gradually recover, and the species containing specific PLFA also increase, which increase the diversity of PLFA [39]. The PLFA diversity index of reactor $\mathrm{A}_{2}$ dropped and reactor $\mathrm{B}_{2}$ remained at a high level, indicating that the $\mathrm{MF}$ had little affect on PLFA diversity of ASM under slow cooling, but had a better strengthening effect on that under rapid cooling. Meanwhile, rapid cooling probably stimulated the cell membrane to produce new PLFA to enhance the cold adaptability [40], which could increase the PLFA diversity of reactor $\mathrm{B}_{2}$.

\section{Polymerase Chain Reaction-Denaturing Gradient Gel Electrophoresis Analysis Comparison of the Four Runs from Denaturing Gradient Gel Electrophoresis}

From Fig. 6, 10 representative bands in four lanes were obtained, and had distinguishing distributions in different lanes. It can be obtained from band quantity that the band quantity with MF strengthening $\left(\mathrm{A}_{2}\right.$ and $\mathrm{B}_{2}$ ) were more than the control groups $\left(\mathrm{A}_{1}\right.$ and $\left.\mathrm{B}_{1}\right)$, and the band quantity of slow cooling and rewarming with $\mathrm{MF}\left(\mathrm{A}_{2}\right)$ were more than that under rapid temperature change conditions with $\mathrm{MF}\left(\mathrm{B}_{2}\right)$.

Bands 1, 4, and 6 belonged to four reactors, and were more intense by comparison, which indicated that this species of bacteria was enriched under the corresponding culture condition. Bands 2, 3, and 8 did not exist in Lanes 1 and 3, but existed in Lanes 2 and 4 , which indicated that the bacteria corresponding to Bands 2, 3, and 8 did not exist in $A_{1}$ and $B_{1}$, but

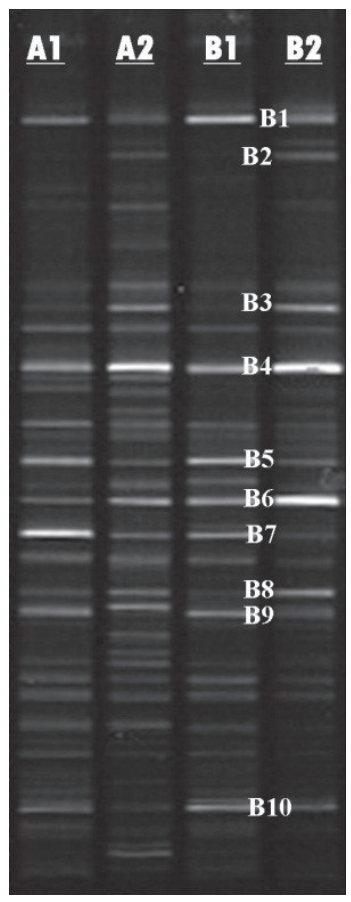

Fig. 6. 16S rRNA analysis of bacterial community structure on different activated sludge reactors for the four runs by PCRDGGE. 
existed in $A_{2}$ and $B_{2}$. The suitation of Band 5 was opposite of Bands 2, 3, and 8, which showed that the bacteria in Band 5 did not exist under low temperature and MF strengthening. Bands 7 and 9 existed in Lanes 1,2 , and 3, but disappered in Lane 4, so the bacteria in Bands 7 and 9 did not enrich in rapid temperature variation conditions with MF. On the contrary, Band 10 just existed in Lanes 1, 3, and 4, which meant that the bacteria in Band 10 was only enriched under rapid cooling and rewarming with MF.

\section{Analysis of Microbial Community}

The ten representative bands were sequenced and blasted with National Center for Biotechnology Information (NCBI).

Band 1 was closely related to Clostridium cellulovoran, in the family of Clostridiaceae. Band 4 was closely related to Dehalogenimonas sp., in the phylum of Chloroflexi. Band 6 was closely related to Flavobacterium indicum, in the family of Flavobacteriaceae. The above-mentioned three kinds of bacteria were common bacteria for four lanes, belonging to dominant bacteria in the reactor operation process.

Band 2 was closely related to Delftia sp., belonging to the Comamonadaceae family, and studies had reported the MF strengthening effect on Delftia to maintain the cell physiological function and activity control [41]. Band 3 was related to Clostridium cellulovorans, in the family of Clostridiaceae. Krauss separated the species by magnetic separation technology in the analysis of the enhancement effect of crystalline cellulose on bacteria activity [42]. Band 8 was related to Flavobacterium branchiophilum, in the family of Flavobacteriaceae, belonging to Gram negative bacteria. Ryumae studied the rapid detection of immune magnetic separation of this bacteria by flow cytometry [43]. The above species all had magnetic biological effect reported by corresponding research, as a result they were enriched under MF strengthening condition. While Band 5 was related to Wolinella succinogenes, in the family of Helicobacteraceae, the disappearance of Band 5 in Lanes 2 and 4 indicated that the bacteria growth was inhibited by MF condition at low temperature.

Band 7 was similar to Novosphingobium sp., in the family of Sphingomonadaceae. Jung et al. found that the low-temperature activity was $40 \%$ higher than that of other species when they studied the epoxide hydrolase activity of this species [44]. Band 9 was related to Burkholderia phytofirmans, belonging to the Burkholderiaceae family. Essaid et al. studied the cold resistance of this species in plant inoculation and found that it could reduce the cold sensitivity of a plant to improve cold resistance ability [45]. The experimental results showed that although the two species had certain cold resistance, they were inhibited by rapid cooling and rewarming under low temperaure. While Band 10 was similar to Klebsiella oxytoca, in the family of
Enterobacteriaceae it was not enriched as affected by MF under slow cooling and rewarming.

\section{Conclusions}

The MF had a better strengthening effect on ASM under slow temperature variation than rapid temperature variation. Rapid temperature variation and continual exposure time at low temperature increased the injury of microbial cells, and inhibited the activity of SOD and CAT. Meanwhile, MF had a definite strengthening effect on SOD activity at low temperature. The MF had a better strengthening effect on the relief and inhibition of cell membrane lipid peroxidation and low-temperature injury indicated by MDA. The MF had little affect on PLFA diversity of ASM under slow cooling, but had better strengthening effect on that under rapid cooling. Optimal MF strengthening application under different temperature variation mode can strengthen the activity and cold resistance of ASM and improve the efficiency of wastewater treatment under low temperature.

\section{Acknowledgements}

This work was supported by the National Natural Science Foundation of China (51508241), the Postdoctoral Science Foundation of China (2015M570418), and the Opening Foundation of Jiangsu Key Laboratory of Environmental Engineering (ZX2015003).

\section{Conflict of Interest}

The authors declare no conflict of interest.

\section{References}

1. CUSIDO J.A., CREMADES L.V. Atomized sludges via spray-drying at low temperatures: An alternative to conventional wastewater treatment plants. Journal of Environmental Management, 105 (3), 61, 2012.

2. SUMINO H., MUROTA R., MIYASHITA A., IMACHI H., OHASHI A., HARADA H., SYUTSUBO K. Treatment of low-strength wastewater in an anaerobic down-flow hanging sponge (AnDHS) reactor at low temperature. Journal of Environmental Science and Health Part a-Toxic/ Hazardous Substances \& Environmental Engineering, 47 (12), 1803, 2012.

3. HULSEN T., BARRY E.M., LU Y., PUYOL D., BATSTONE D.J. Low temperature treatment of domestic wastewater by purple phototrophic bacteria: Performance, activity, and community. Water Research, 100, 537, 2016.

4. ZHANG C.Q., WANG G.Z., HU Z.Q. Changes in wastewater treatment performance and activated sludge properties of a membrane bioreactor at low temperature operation. Environmental Science-Processes \& Impacts, 16 (9), 21992014 
5. OLIVE P.L., BANATH J.P. The comet assay: a method to measure DNA damage in individual cells. Nature. Protocols, 1 (1), 23, 2006.

6. IMAHORI Y., TAKEMURA M., BAI J. Chilling-induced oxidative stress and antioxidant responses in mume (Prunus mume) fruit during low temperature storage. Postharvest Biology and Technology, 49 (1), 54, 2008.

7. KRUGLOVA A., GONZALEZ-MARTINEZ A., KRAKSTROM M., MIKOLA A., VAHALA R. Bacterial diversity and population shifts driven by spotlight wastewater micropollutants in low-temperature highly nitrifying activated sludge. Science of the Total Environment, 605, 291, 2017.

8. TOMSKA A., WOLNY L.. Enhancement of biological wastewater treatment by magnetic field exposure. Desalination, 222 (1), 368, 2008.

9. NIU C., GENG J.J., REN H.Q., DING L.L., XU K., LIANG W.H. The strengthening effect of a static magnetic field on activated sludge activity at low temperature. Bioresource Technology, 150 (4), 156, 2013.

10. 1NIU C., LIANG W.H., REN H.Q., GENG J.J., DING L.L., XU K.. Enhancement of activated sludge activity by 10 $50 \mathrm{mT}$ static magnetic field intensity at low temperature. Bioresource Technology, 159 (159), 48, 2014.

11. BREWER S., TECHTMANN S.M., MAHMOUDI N., NIANG D., PFIFFNER S., HAZEN T.C. Co-extraction of DNA and PLFA from soil samples. Journal of Microbiological Methods, 115, 64, 2015.

12. SCHWARZENAUER T., ILLMER P. PLFA profiles for microbial community monitoring in anaerobic digestion. Folia Microbiologica, 57 (4), 331, 2012.

13. TRACEY BURDOCK, MARIANNE BROOKS, ABDEL GHALY, DEEPIKA DAVE. Effect of assay conditions on the measurement of dehydrogenase activity of Streptomyces venezuelae using triphenyl tetrazolium chloride. Advances in Bioscience and Biotechnology, 2 (4), 214, 2011

14. WIXON D.L., BALSER T.C. Toward conceptual clarity: PLFA in warmed soils. Soil Biology \& Biochemistry, 57 (3), 769, 2013.

15. PAWLETT M., RITZ K., DOREY R.A., ROCKS S., RAMSDEN J., HARRIS J.A. The impact of zero-valent iron nanoparticles upon soil microbial communities is context dependent. Environmental Science and Pollution Research, 20 (2), 1041, 2013.

16. SMITHWICK E.A.H., TURNER M.G., METZGER K.L., BALSER T.C. Variation in $\mathrm{NH}_{4}^{+}$mineralization and microbial communities with stand age in lodgepole pine (Pinus contorta) forests, Yellowstone National Park (USA). Soil Biology and Biochemistry, 37 (8), 1546, 2005.

17. CHAUDHARY D.R., DICK R.P. Identification of Metabolically Active Rhizosphere Microorganisms by Stable Isotopic Probing of PLFA in Switchgrass. Communications in Soil Science and Plant Analysis, 47 (21), 2433, 2016

18. KAYRANLI B., UGURLU A. Effects of temperature and biomass concentration on the performance of anaerobic sequencing batch reactor treating low strength wastewater. Desalination, 278 (1), 77, 2011.

19. KINNUNEN V., RINTALA J. The effect of lowtemperature pretreatment on the solubilization and biomethane potential of microalgae biomass grown in synthetic and wastewater media. Bioresource Technology, 221, 78, 2016.

20. IL'IN V.I., PERFIL'EVA A.V., KOLESNIKOV V.A. Effect of magnetic field on the electroflotation extraction of sparingly water-soluble heavy and non-ferrous metal compounds from wastewater. Russian Journal of General Chemistry, 84 (11), 2315, 2014.

21. LIU Y.Q., SUHARTINI S., GUO L., XIONG Y.P. Improved biological wastewater treatment and sludge characteristics by applying magnetic field to aerobic granules. Aims Bioengineering, 3 (4), 412, 2016.

22. FILIPIC J., KRAIGHER B., TEPUS B., KOKOL V., MANDIC-MULEC I.. Effects of low-density static magnetic fields on the growth and activities of wastewater bacteria Escherichia coli and Pseudomonas putida. Bioresource technology, 120 (5), 225, 2012.

23. LI H.B., ZHOU B.H., TIAN Z.Y., SONG Y.H., XIANG L.C., WANG S.Y., SUN C. Efficient biological nitrogen removal by Johannesburg-Sulfur autotrophic denitrification from low $\mathrm{COD} / \mathrm{TN}$ ratio municipal wastewater at low temperature. Environmental Earth Sciences, 73 (9), 5027, 2015.

24. TOSTI S., ACCETTA C., FABBRICINO M., SANSOVINI M., PONTONI L. Reforming of olive mill wastewater through a Pd-membrane reactor. International Journal of Hydrogen Energy, 38 (25), 10252, 2013.

25. ZAIDI N.S., SOHAILI J., MUDA K., SILLANPAA M. Magnetic Field Application and its Potential in Water and Wastewater Treatment Systems. Separation and Purification Reviews, 43 (3), 206, 2014.

26. TAO Q.Q., ZHOU S.Q. Effect of static magnetic field on electricity production and wastewater treatment in microbial fuel cells. Applied Microbiology and Biotechnology, 98 (23), 9879, 2014.

27. GUO J., WANG J., CUI, D., WANG L., MA F., CHANG C.C., YANG J. Application of bioaugmentation in the rapid start-up and stable operation of biological processes for municipal wastewater treatment at low temperatures. Bioresource Technology, 101 (17), 6622, 2010.

28. ZAADY E., BEN-DAVID E.A., SHER Y., TZIRKIN R., NEJIDAT A. Inferring biological soil crust successional stage using combined PLFA, DGGE, physical and biophysiological analyses. Soil Biology and Biochemistry, $42(5), 842,2010$.

29. XU G.J., XU X.C., YANG F.L., LIU S.T., GAO Y. Partial nitrification adjusted by hydroxylamine in aerobic granules under high DO and ambient temperature and subsequent Anammox for low $\mathrm{C} / \mathrm{N}$ wastewater treatment. Chemical Engineering Journal, 213 (12), 338, 2012.

30. TU R.J., JIN W.B., XI T.T., YANG Q., HAN S.F., ABOMOHRA A. Effect of static magnetic field on the oxygen production of Scenedesmus obliquus cultivated in municipal wastewater. Water Research, 86, $132,2015$.

31. GILBERT E.M., AGRAWAL S., KARST S.M., HORN H., NIELSEN P.H., LACKNER S. Low Temperature Partial Nitritation/Anammox in a Moving Bed Biofilm Reactor Treating Low Strength Wastewater. Environmental Science \& Technology, 48 (15), 87842, 2014.

32. AZIMI N., HASSANI A.H., DARZI G.N., BORGHEI S.M. Biodegradation of Wastewater Containing High Concentration of Sulfamethoxazole by Antibiotic Adopted Biofilm in Attached Growth Bioreactor. Polish Journal of Environmental Studies, 26 (6), 2463, 2017.

33. ZANOTTO C., BISSA M., ILLIANO E., MEZZANOTTE V., MARAZZI F., TUROLLA A., ANTONELLI M., MORGHEN C.D., RADAELLI A. Identification of antibiotic-resistant Escherichia coli isolated from a municipal wastewater treatment plant. Chemosphere, 164, 627, 2016 
34. LARIBI-HABCHI H., BOUANANE-DARENFED A., DROUICHE N., PAUSS A., MAMERI N. Purification, characterization, and molecular cloning of an extracellular chitinase from Bacillus licheniformis stain LHH100 isolated from wastewater samples in Algeria. International Journal of Biological Macromolecules, 72, 1117, 2015.

35. CHEN J.F., NIE Q.S., ZHANG Y., HU,J.Z., QING L. Eco-physiological characteristics of Pistia stratiotes and its removal of pollutants from livestock wastewater. Water Science and Technology, 69 (12), 2510, 2014.

36. YASMEEN T., ALI Q., ISLAM F., NOMAN A., AKRAM M.S., JAVED M.T. Biologically treated wastewater fertigation induced growth and yield enhancement effects in Vigna radiata L. Agricultural Water Management, 146, 124, 2014.

37. YANG K.L., YUE Q.Y., HAN W., KONG J.J., GAO B.Y., ZHAO P., DUAN L. Effect of novel sludge and coal cinder ceramic media in combined anaerobic-aerobic bio-filter for tetracycline wastewater treatment at low temperature. Chemical Engineering Journal, 277, 130, 2015.

38. MA B., PENG Y.Z., ZHANG S.J., WANG J.M., GAN Y.P., CHANG J., WANG S.Y., ZHU G.B. Performance of anammox UASB reactor treating low strength wastewater under moderate and low temperatures. Bioresource Technology, 129 (2), 606, 2013.

39. SHENTU J.L., HE Z.L., ZENG Y.Y., HE S.Y., DU S.T., SHEN D.S. Microbial Biomass and PLFA Profile Changes in Rhizosphere of Pakchoi (Brassica chinensis L.) as Affected by External Cadmium Loading. Pedosphere, 24 (4), 553, 2014.
40. TUNC E., GUL O. Analysis of phospholipid fatty acids (PLFA) as a soil bioindicator in karkamis/gaziantep pistachio orchards. Fresenius Environmental Bulletin, 23 (2), 385, 2014.

41. PARK J.H., YANG S.H., LEE J., KO E.H., HONG D., CHOI I.S. Nanocoating of Single Cells: From Maintenance of Cell Viability to Manipulation of Cellular Activities. Advanced Materials, 26 (13), 2001, 2014.

42. KRAUSS J., ZVERLOV V.V., SCHWARZ W.H. In Vitro reconstitution of the complete clostridium thermocellum cellulosome and synergistic activity on crystalline cellulose. Applied and Environmental Microbiology, 78 (12), 4301, 2012.

43. RYUMAE U., HIBI K., YOSHIURA Y., REN H.F., ENDO H. Rapid and highly sensitive detection of Flavobacterium psychrophilum using high gradient immunomagnetic separation with flow cytometry. Aquaculture, 309 (1), 125, 2010.

44. WOO J.H., KANG J.H., KANG S., HWANG Y.O., KIM S.J. Cloning and characterization of an epoxide hydrolase from Novosphingobium aromaticivorans. Applied Microbiology and Biotechnology, 82 (5), 873, 2009.

45. ESSAID AIT BARKA, NOWAK J., CHRISTOPHE CLÉMENT Enhancement of Chilling resistance of enoculated grapevine plantlets with a plant growthpromoting rhizobacterium, Burkholderia phytofirmans strain PsJN. Applied and Environmental Microbiology, 72 (11), 7246, 2006 